\title{
LA PENETRACION DE LAS REDES DE TRASHUMANCIA CASTELLANA EN LA SIERRA NORTE DE SEVILLA
}

\author{
María Antonia Carmona Ruiz \\ Universidad de Sevilla
}

Tras la reconquista del Valle del Guadalquivir y la institucionalización del Honrado Concejo de la Mesta, Alfonso X dividió su reino en cinco distritos ganaderos con el fin de establecer un justo cobro del servicio de los ganados trashumantes, quedando el reino de Sevilla incluido en uno de estos distritos, y haciéndose referencia a una cañada que iba por el Guadalquivir hasta el mar $^{1}$. Esto nos puede llevar a presuponer la presencia de trashumantes en el territorio sevillano, aunque con reservas ya que en esta división quedan englobados todos los territorios del reino castellano, por lo que se podría pensar que más que de una realidad, el documento en cuestión parte de una posibilidad de encontrar ganado mesteño en cualquier lugar del reino. De hecho, muchísimos autores han olvidado el sur peninsular a la hora de realizar un estudio de las redes de trashumancia hispana ${ }^{2}$.

Sin embargo, los últimos estudios sobre la ganadería andaluza han demostrado la presencia durante la Baja Edad Media de los ganados trashumantes en el Alto y Medio Guadalquivir ${ }^{3}$. Del mismo modo, hemos podido constatar la llegada de ganados trashumantes al menos a la zona Norte del reino de Sevilla, en concreto al concejo de Fregenal de la Sierra, así como a las villas de la actual Sierra de Huelva, poblaciones pertenecientes durante

1 1272, octubre, 3. Burgos. Publicado por Manuel GonzÁlez JimÉnez, Diplomatario andaluz de Alfonso $X$, Sevilla, 1991 , doc. $n^{\circ} 398$.

2 En este sentido destacan las obras: Descripción de las Cañadas Reales de León, Segovia, Soria y ramales de la de Cuenca y del valle de Alcudia, reed. Madrid, 1984. Marie-Claude GERBET, La noblesse dans le royaume de Castille. Étude sur les structures sociales en Extrémadures du 1454 a 1516, Paris, 1979, pp. 91-93. L'elevage dans le royaume de Castille sous les Rois Catholiques (1454-1516), Madrid, 1991, p. 50.

3 Vid. Carmen ARgente del Castillo OcaNa, la ganadería medieval andaluza. Siglos XIII-XVI (reinos de Jaín y Cordoba), Jaén, 1991, pp. 283 y ss. 
la Baja Edad Media a la "tierra" de Sevilla, dentro del distrito de la Sierra Norte.

El ganado mesteño que se trasladaba a estos lugares serranos se beneficiaba del hecho de ser una zona donde las tierras de cultivo no eran muchas, predominando pues los baldíos y los montes comunales de uso eminentemente ganadero.

La excepción a esta realidad se encuentra en el concejo de Fregenal y las villas vecinas de Bodonal e Higuera la Real, ya que su emplazamiento en un valle permitía un mayor desarrolo agrícola que cualquiera de sus vecinos, riqueza que Sevilla intentó preservar.

Por ello, las principales noticias que poseemos de la presencia de ganados trashumantes en esta zona se refieren a estas localidades, ya que se hizo necesario el trazado unos lugares de paso para estos animales, con el fin de proteger los cultivos. La importancia agrícola de las demás localidades era más bien escasa por lo que los problemas de invasión de los cultivos por el ganado en busca de alimento tuvieron que ser mínimos, con lo que no hubo necesidad de procurar el trazado de cañadas.

Los ganados trashumantes que llegaban a la Sierra Norte de Sevilla tras haber atravesado las tierras de la Orden de Santiago, continuaban su camino hasta la zona del Andévalo y Portugal ${ }^{4}$ aprovechándose del pasto de las tierras comunales de las villas por las que pasaban y arrendando dehesas en que alimentarses.

La procedencia de estos ganados tuvo que ser de lo más variada, aunque la gran mayoría fuera de origen soriano. Esto se puede constatar por el hecho de que en la documentación se hacen múltiples referencias a "ganados sorianos», como sinónimo de ganado trashumante. Así, además de encontrarnos ganados de procedencia soriana, tenemos noticias de la llegada de ganados segovianos y logroñeses ${ }^{6}$.

Una de las primeras noticias que tenemos de la relación de la comarca de la Sierra con los ganados trashumantes data de 1338, año en que Juan Martínez de la Yna, alcalde y "guarda mayor del cuerpo del rey», declaró libre de cañadas «extremas» el término de Higuera la Real. A pesar del veredicto, los ganados trashumantes continuaron penetrando en el término de esta villa, con lo que la sentencia se ratificó en 1416 por Juan Fernández

${ }^{4}$ (A)rchivo (M)unicipal de (S)evilla, Secc. I, carp. 59, $\mathrm{n}^{\circ} 4$.

s Así, conocemos el arrendamiento a pastores trashumantes de las dehesas de Corte de Lana y Tierras del Rosal, en término de Aroche. 1568, octubre. Archivo Municipal de Aroche. Actas Capitulares, $n^{\circ} 3$.

6 Hemos constatado en la villa de Aroche la presencia de pastores procedentes de Montenegro de Cameros (Soria), Lumbreras (Logroño) y Villoslada (Segovia). Archivo Municipal de Aroche, Actas Capitulares, tomo 3. 
de Mendoza, alcalde mayor de Sevilla. Así, este alcalde ordenó que ningund soriano ni otra persona alguna que sea pasen por término dese dicho logar con sus ganados ni fagan cañadas ni fuellen la tierra, saluo aquellas que fasta aqui lo fazian e con derecho deuen pasar su ganado por ay e non otro alguno ${ }^{7}$. La necesidad de impedir el paso de ganado trashumante por esta villa podía proceder de la falta de pasto abundante para estos animales, debido a la importancia de la cabaña local, que por hambre provocaban importantes daños en los cultivos aledaños a los caminos por los que transitaban, y de las quejas de los vecinos por el daño que podían haber producido en la agricultura. Lo cierto es que la llegada de ganados trashumantes al concejo de Higuera la Real prosiguió, con lo que continuaron las quejas respecto a la entrada de ganados trashumantes en Higuera la Real.

Pero los principales conflictos con los trashumantes se produjeron en el concejo de Fregenal de la Sierra, donde los vecinos se quejaron de la invasión de sus cultivos por estos ganados al salirse de los caminos designados para esu tránsito, provocando importantes daños a la agricultura de la zona. Como contrapartida, los agricultores ocupaban las cañadas colindantes con sus tierras. Los enfrentamientos que tuvieron lugar hicieron que en 1410 Domingo Fernández y Pedro García, pastores sorianos, vasallos del adelantado Pedro Manrique, pidieran al concejo de Sevilla cañadas. Esta petición fue remitida a los alcaldes de Fregenal, mandándoles que les dejaran pasar por las cañadas por donde antiguamente pasaban ${ }^{8}$. Ante esta orden, los alcaldes de Fregenal, tras realizar algunas investigaciones señalaron dos cañadas que se utilizaban tiempo atrás ${ }^{9}$. Una de ellas tenía trazado NorteSur, mientras que la otra tenía dirección Noroeste-Sureste, entrando esta última en el término de Fregenal por la zona de Valencia del Ventoso ${ }^{10}$.

Sin embargo los sorianos no utilizaron exclusivamente estas vías pecuarias para su paso por los concejos de Bodonal y Fregenal en busca de alimento. Así, cuando iban a las tierras adehesadas de los vecinos de Fregenal para comprar el pasto, los ganados abandonaban estos caminos y se a adentraban en sembrados y viñedos, destrozando los cultivos que en su camino encontraban. Las quejas de los vecinos llevó a que en 1417 Pedro Fernández de Jerez, veinticuatro y juez nombrado por Sevilla, tras una investigación señalara una cañada que, utilizando la que iba desde Segura de León a

7 Archivo Municipal de Sevilla, Secc. $1^{2}$, carp. 59, n $n^{\circ}$, cuaderno 4.

8 AMS, Secc. $1^{2}$, carp. $59, n^{\circ} 4$, cuaderno 3.

9 Ibidem.

10 «Porque vos mando a vos e a cada vno de vos que les dexedes pasar por todas las cañadas que antiguamente se acostunbraron desenbargadamente e les non enbargades, e que los dexedes pasar por la fuente de los Berros e por la Parra e por todas las cañadas acostumbradas, e guardando pan e vino" (AMS, Secc. I, carp. 59, $n^{\circ} 4$, cuad. 3). 
Huelva, atravesara el río Ardila, pasara por Bodonal, y siguiera hasta Fregenal, cruzando el arroyo de las Tablas donde se hacía la feria de ganado, para pasar después por la sierra de S. Cristóbal y de ahí ir hasta la dehesa del Caño ${ }^{11}$. El trazado de esta nueva cañada implicaba el hecho de que los sorianos dejarían de usar las que utilizaban hasta ese momento. Es probable que esta orden se cumpliera, pero pronto los ganados trashumantes volvieron a utilizar las antiguas cañadas que a través de las tierras de la Orden de Santiago los trasladaban a Bodonal y Fregenal ${ }^{12}$.

Desconocemos totalmente la categoría de las vías pecuarias que se habilitaron para el paso del ganado trashumantes por los concejos estudiados. En ningún momento se alude a la anchura de los caminos ganaderos utilizados por los ganados sorianos en la documentación analizada. El empleo generalizado de la palabra «cañada» al referirse a una vía pecuaría no nos puede llevar a la suposición de que todos los caminos utilizados por los trashumantes tuvieran esa categoría.

Los intereses de estos concejos y de Sevilla en que los ganados sorianos entraran en su territorio quedan claramente patentes con el hecho de facilitarles accesos. El concejo de Sevilla se beneficiaba particularmente de la venta de la hierba de la dehesa del Caño, perteneciente a los bienes de propios de la ciudad, aprovechándose los concejos de la Sierra del arrendamiento de dehesas para el pasto de este ganado. Además estas villas obtenían otros beneficios, no menos importantes, derivados del contacto comercial con los que atravesaban estas rutas ${ }^{13}$. Por todo ello, procurarían que se respetaran las cañadas, impidiendo su ocupación por los agricultores que las estrechaban plantando vides ${ }^{14}$.

En cuanto a los vecinos del concejo de Fregenal, se intentaron aprovechar de la situación adehesando indebidamente sus tierras, impidiendo su uso temporal por el ganado local, y vendiéndolas especialmente a los ganados trashumantes. Este hecho produjo un pleito, cuya sentencia, dada en 1417, se pronunció a favor el pasto común, como era norma en la tierra de Sevilla, beneficiándose claramente a los pequeños ganaderos que ante la imposibilidad de uso de estos pastos emigraban a tierras de la Orden de Santiago. Esto podía haber provocado un paulatino despoblamiento de la zona, por lo que el concejo de Sevilla puso todos los medios disponibles para evitarlo.

11 AMS, Secc. $1^{\circ}$, carp. $59, n^{\circ} 4$, cuadernos 6 y 8.

12 Un estudio exhaustivo de las cañadas que conducían a los ganados trashumantes a estos lugares se encuentra en el libro dirigido por P. GARCin MARTin, Cañadas, cordeles y veredas, Valladolid, 1991. Ver también el libro Descripción de las Cañadas Reales, Madrid, Ed. Museo Universal, 1984.

13 Mercedes Borrero Fernandez, El Concejo de Fregenal: poblacion y economía en el siglo $X V$, «Historia, Instituciones, Documentos», 5 (1978), p. 158.

${ }^{14}$ AMS, Secc. $1^{2}$, carp. $59, n^{\circ} 4$, cuaderno 4. 


\section{POSIBLES VIAS DE PENETRACION DE LA TRASHUMANCIA EN LA TIERRA DE SEVILLA}

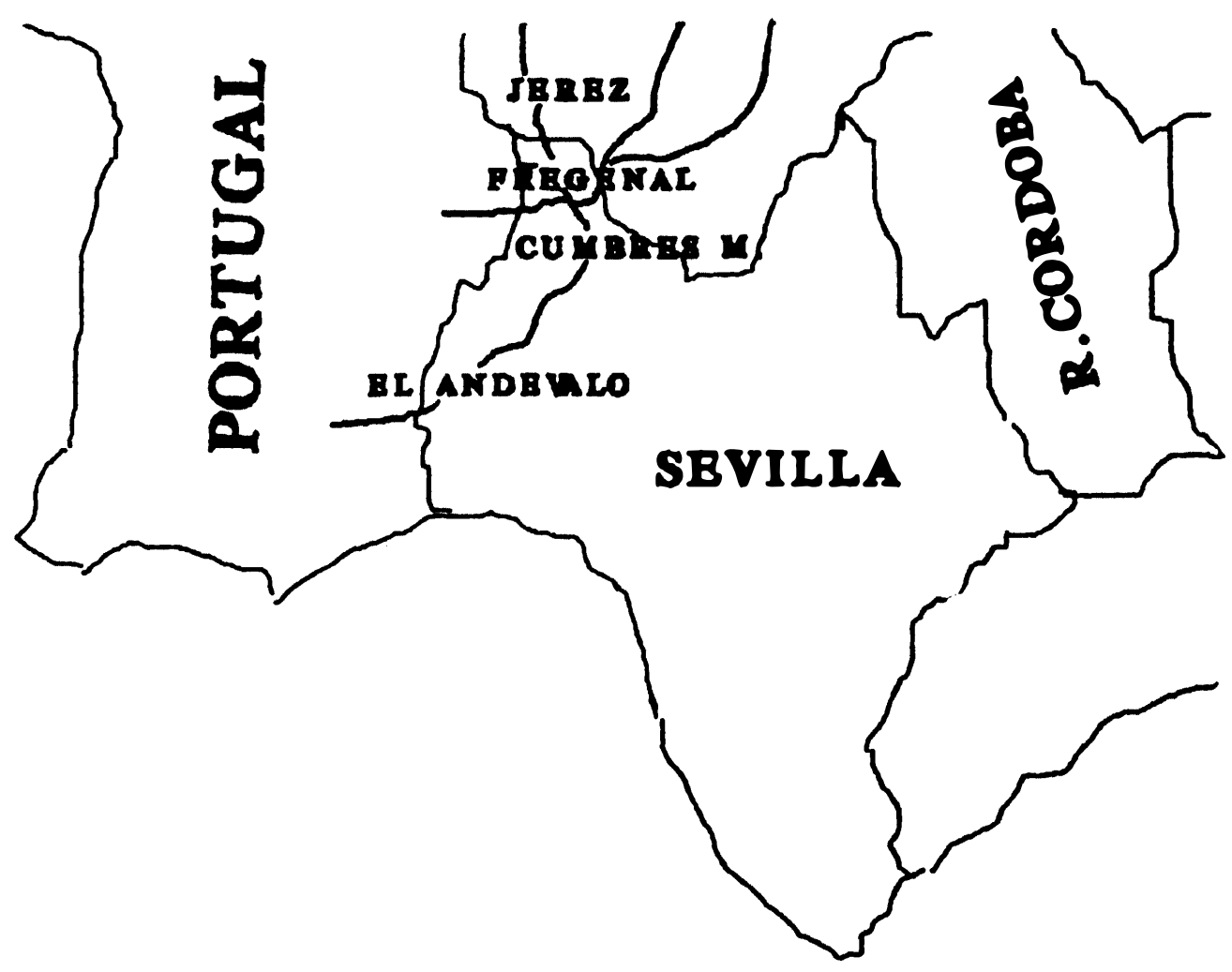




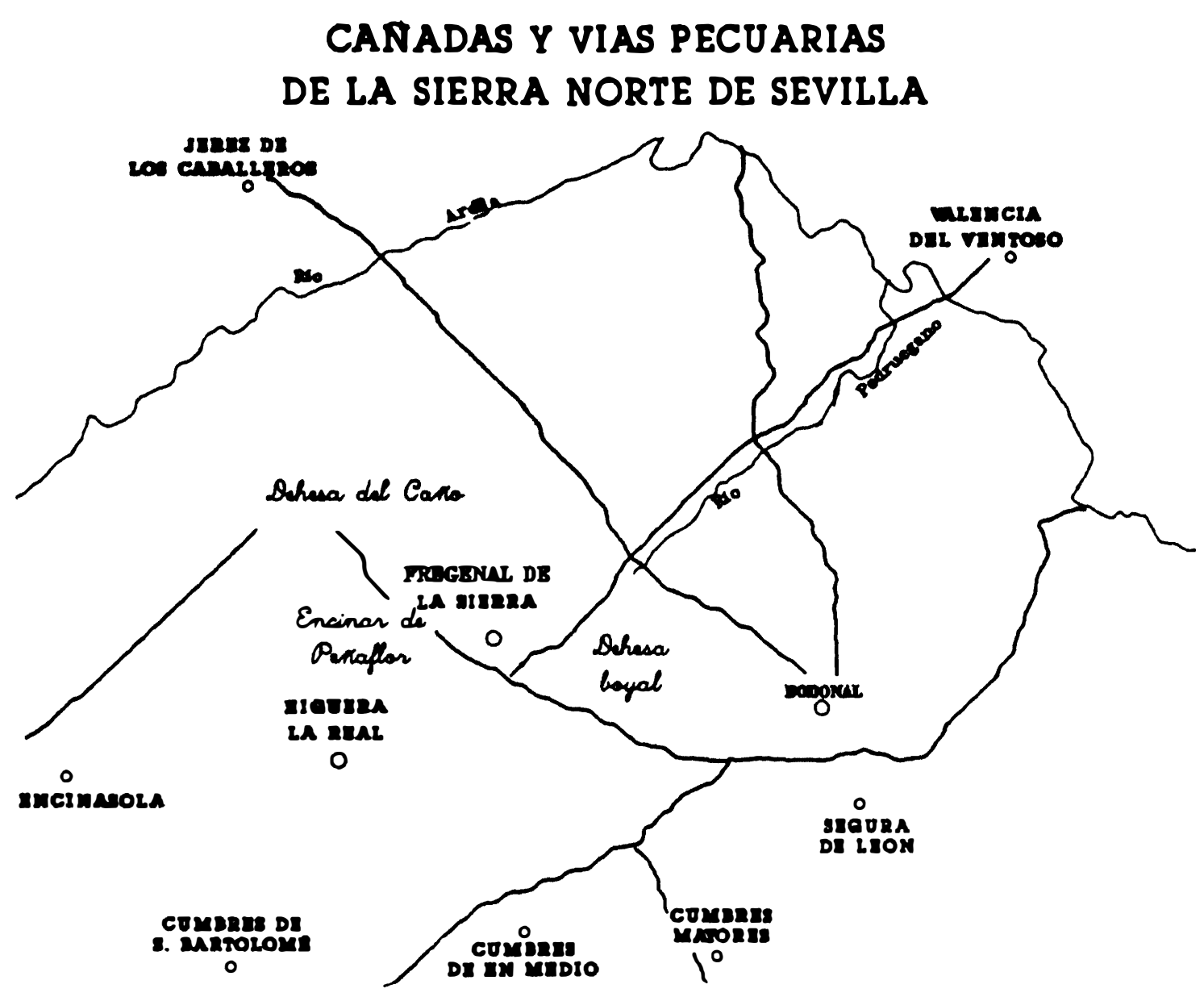


El privilegio que obtuvo Sevilla de exención de visitas del alcalde entregador ${ }^{15}$ hizo que la justicia local se encargara, como en el caso al que estamos haciendo referencia, de solucionar los problemas concernientes al Honrado Concejo de la Mesta, de los que en circunstancias normales debía haberse ocupado este funcionario real o los jueces de Mesta. Este hecho reforzaría el papel de Sevilla frente al Real Concejo que llevó a que su actitud ante a las pretensiones de la Mesta de impedir que los almojarifes de Fregenal cobrasen derechos sobre el ganado que por allí pasaba, fuera la de defender a su villa alegando que siempre obtuvieron portazgo y almojarifazgo del ganado de esa zona ${ }^{16}$.

El cobro de portazgo y almojarifazgo a los ganados mesteños en el territorio de Sevilla llevó a un pleito que se produjo en 1488 entre la ciudad de Sevilla y el concejo de La Mesta "espeçialmente de los ganados que pasan por las villas de Frexenal e Cortegana e Cumbres Mayores e por otros lugares e villas de la tierra de la dicha şibdat ${ }^{17}$. Ante tal acusación, el concejo de Sevilla alegó en su defensa que siempre lo habían cobrado en esa zona. No conservamos tal privilegio, pero en otros documentos dados por Alfonso $\mathrm{X}$ en que se exime a los ganados de otras localidades del pago de portazgos y montazgos, se obligaba al pago de estos impuestos en Sevilla, Toledo y Murcia ${ }^{18}$. El cobro de este gravamen al ganado mesteño en Sevilla está testificado además con el hecho de que en 1432 Juan Gómez, mayordomo de Cumbres Mayores, recibiera por el portazgo de los ganados trashumantes que pasaron por su territorio $376 \mathrm{mrs}^{19}$.

Así pues, los trashumantes que llegaron a la comarca de la Sierra de Sevilla se encontraron con los mismos problemas que se le plantearon en el resto de Castilla: los intentos de restricción de la libertad de pastos, la imposición de arbitrios locales y el enfrentamiento con los agricultores por la invasión de los cultivos. Aunque la monarquía intentó proteger a este preciado ganado mediante privilegios especiales, sin embargo estos chocaron frontalmente con las exenciones locales y no siempre pudieron ponerse en práctica.

15 Julius KLein, La Mesta, Madrid, 1990. p. 114.

16 AMS, Act. Cap., 1488-XII-16.

17 AMS, Tumbo de los RR.CC., IV, 288-9.

18 1272, abril, 12, Murcia. Privilegio dado por Alfonso X a Baeza, eximiéndoles del pago de portazgos y montazgos, «si non fuere en Toledo e en Sevilla e en Murçia». Publ. por M.GoNZAlez Diplomatario andaluz... op. cit. doc. $n^{\circ} 393$.

19 AMS, Secc. XVI, n' 134. 


\section{RÉSUMÉ}

Bien que les travaux, déjà classiques, traitant de la "Mesta» (association des éleveurs de moutons transhumants espagnols au Moyen-Age) et de la transhumance oublie le sud de la péninsule Ibérique, les études récentes sur l'élevage andalous ont pu démontrer comment les résseaux de transhumance espagnols atteignirent la région du Guadalquivir, et plus concrètement le royaume de Séville. Nous pouvons ainsi découvrir une voie de pénétration de l'élevage de la "Mesta" dans les terres sévillanes, voie qui passait par ce que l'on appelle actuellement la Sierra de Huelva et qui arrivait au moins à Andévalo.

Le pâturage abondant que rencontrait l'élevage dants cette région, incita de nombreux bergers à s'y déplacer avec leurs troupeaux. Ils venaient de régions aussi éloignées que Soria ou Logroño. Ils trouvèrent cependant sur leur chemin quelques bourgades (en particulier Fregenal de la Sierra) où la richesse agricole était plus importante, ce qui rendit nécessaire, pour protéger les cultures, de tracer des voies de passage pour les animaux. Malgré les précautions prises, il y eut de nombreaux affrontements entre les éleveurs et les agriculteurs, affrontements qui amenèrent à la création de nouveaux passages pour le déplacement des troupeaux transhumants.

\section{SUMMARY}

Though the already classical analyses of the Mesta (Association of Spanish transhumant sheep breeders during the Middle Ages) and transhumance systematically forget the South of the Spanish Peninsula, recent studies on Andalousian stockbreeding demonstrated how Hispanic transhumance networks reached the area of the Guadalquivir and, more precisely, the Reign of Sevilla. We can thus observe a way of penetration of the Mesta cattle in the Sevillian region through the nowadays called Sierra de Huelva that reached, at least, Andévalo.

The optimum conditions that the cattle found to feed itself in this area encouraged several shepherds to move with their herds from remote places such as Soria or Logroño. Nevertheless, on their way they found some towns (specially Fregenal de la Sierra) where farming wealth was greater and special paths for the animals were designed to protect crops. Despite preventive measures that were taken, important confrontations between stockbreeders and farmers took place and new cattle tracks were made to make transhumance easier. 